\title{
Laparoendoscopic Single Site Surgery for the Treatment of Huge Ovarian Cysts Using an Angiocatheter Needle
}

\author{
Eun Young Ki, Eun Kyung Park, In Cheol Jeong, Sung Eun Bak, \\ Hye Sung Hwang, Yoo Hyun Chung, and Min Jong Song \\ Department of Obstetrics and Gynecology, Daejeon St. Mary's Hospital, College of Medicine, The Catholic University of Korea, Daejeon, Korea.
}

Purpose: The aim of this study was to evaluate the feasibility and safety of laparoendoscopic single site (LESS) surgery using an angiocatheter needle in patients with huge ovarian cysts (diameter $\geq 15 \mathrm{~cm}$ ).

Materials and Methods: Thirty-one patients with huge ovarian cysts underwent LESS surgery using an angiocatheter needle between March 2011 and August 2016. An intra-umbilical vertical incision (1.5-2.0 cm) was made in the midline. After the cyst wall was punctured using an angiocatheter needle, the fluid contents were aspirated with a connected vacuum aspirator. After placing a Glove port in the umbilical incision, LESS surgery was performed using a rigid 0-degree, 5-mm laparoscope and conventional, rigid, straight laparoscopic instruments. Knife-in-bag morcellation was instituted for specimen collection.

Results: The median maximal diameter of ovarian cysts was $18 \mathrm{~cm}$ (range, $15-30 \mathrm{~cm}$ ), the median operation time was 150 minutes (range, 80-520 minutes), and the median volume of blood loss was $100 \mathrm{~mL}$ (range, 20-800 mL). Three patients (9.7\%) were diagnosed with malignant ovarian cancer using intraoperative frozen examination, and 1 patient was converted to laparotomy due to advanced disease. Thirty patients underwent LESS, and there was no need for an additional laparoscopic port.

Conclusion: LESS surgery using an angiocatheter needle, with leaving only a small postoperative scar, was deemed feasible for the management of huge ovarian cysts.

Key Words: Huge ovarian cyst, LESS surgery, feasibility, safety

\section{INTRODUCTION}

The incidences of ovarian tumors are reported as $0.17 \%$ to $5.9 \%$ in asymptomatic women and $7.1 \%$ to $12 \%$ in symptomatic women. ${ }^{1}$ Laparoscopic management of benign ovarian cysts is common and offers advantages of short hospital stay, small postoperative scars, decreased formation of postopera-

\footnotetext{
Received: April 1, 2019 Revised: June 14, 2019

Accepted: July 5, 2019

Corresponding author: Min Jong Song, MD, PhD, Department of Obstetrics and Gynecology, Daejeon St. Mary's Hospital, College of Medicine, The Catholic University of Korea, 64 Daeheung-ro, Joong-gu, Daejeon 34943, Korea.

Tel: 82-42-220-9550, Fax: 82-42-253-9464, E-mail: bitsugar@catholic.ac.kr

-The authors have no potential conflicts of interest to disclose.

(C) Copyright: Yonsei University College of Medicine 2019

This is an Open Access article distributed under the terms of the Creative Commons Attribution Non-Commercial License (https://creativecommons.org/licenses/ by-nc/4.0) which permits unrestricted non-commercial use, distribution, and reproduction in any medium, provided the original work is properly cited.
}

tive adhesion, and decreased postoperative pain. ${ }^{2,3}$ However, laparoscopic surgery has some limitations, including ovarian cyst rupture, tumor spillage, incomplete tumor excision, trocar site metastasis, and direct seeding of cancer cells. ${ }^{4-6}$ Thus, surgery for a huge ovarian cyst with suspected malignancy should be extirpated by classic laparotomy using a vertical midline incision.

With advances in surgical techniques and instruments, many minimally invasive surgical procedures have been developed to treat huge ovarian cysts with favorable clinical outcomes. Laparoendoscopic single site (LESS) surgery, also known as single-port laparoscopic surgery, is a minimally invasive surgery and has garnered considerable interest in gynecology. ${ }^{7}$ The surgery is performed through a single transumbilical incision, which allows for excellent cosmetic results and minimizes potential morbidities associated with multiple or large incisions. $^{8}$

Single-port surgery has been attempted to prevent spillage 
or cyst rupture during operations. However, previous studies have reported that spillage of cyst fluid contents occurs frequently. Accordingly, the surgical procedure has been combined with intracorporeal and extracorporeal (not solely laparoendoscopic method) or multiport procedures. ${ }^{1-3,7,9}$ Therefore, there is a need for a new method to avoid spillage of cyst contents and to strengthen the advantages of LESS surgery. The aim of this study was to evaluate the feasibility and safety of LESS surgery using an angiocatheter needle in patients with extremely huge (diameter $>15 \mathrm{~cm}$ ) ovarian cysts.

\section{MATERIALS AND METHODS}

\section{Study design and patients characteristics}

We reviewed the medical records of patients with huge ovarian cysts who underwent LESS surgery using an angiocatheter needle between March 2011 and August 2016 at Daejeon St. Mary's Hospital. This study was approved by the Institutional Review Board of the Catholic University of Korea (DC18RESI0090). We ensured that the work described has been carried out in accordance with the Declaration of Helsinki, and informed consent was obtained from each patient.

Patients who met the following inclusion criteria were included in this study: (1) those aged $\geq 13$ and $<85$ years, (2) those with ovarian cysts with a minimum diameter of $\geq 15 \mathrm{~cm}$, (3) those with a general condition appropriate for laparoscopic surgery, and (4) those who received imaging studies, such as ultrasound, computed tomography (CT), or magnetic resonance imaging (MRI). All of the imaging studies revealed a solitary ovarian cyst without any extraovarian disease. Blood tests for tumor markers including CA125 and CA19-9 were performed. We excluded the following patients: (1) those in pregnancy, (2) those whose results of ultrasound, CT, or MRI showed advanced cancer, and (3) those who were previously diagnosed with malignant disease.

\section{Surgical procedures}

All of the surgical procedures were performed under endotracheal general anesthesia in a dorsal lithotomy position. A vertical skin incision between 1.5 and $2.0 \mathrm{~cm}$ in length was made, followed by fascial and peritoneal incision in the midline of
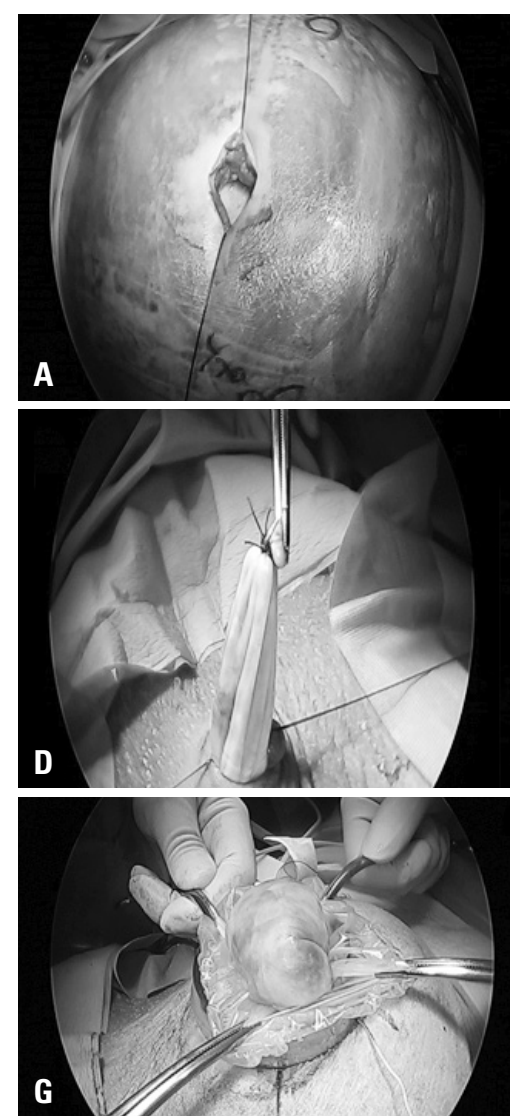
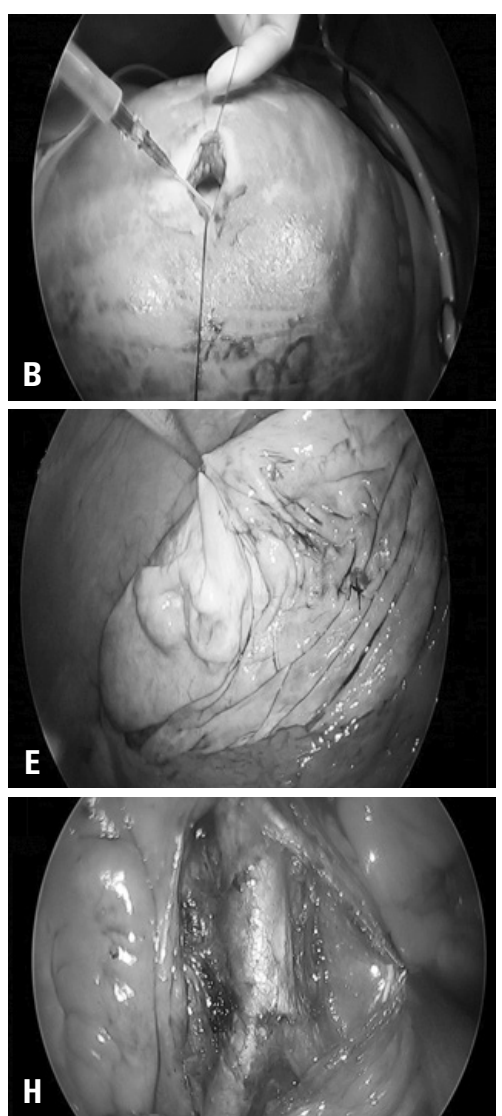
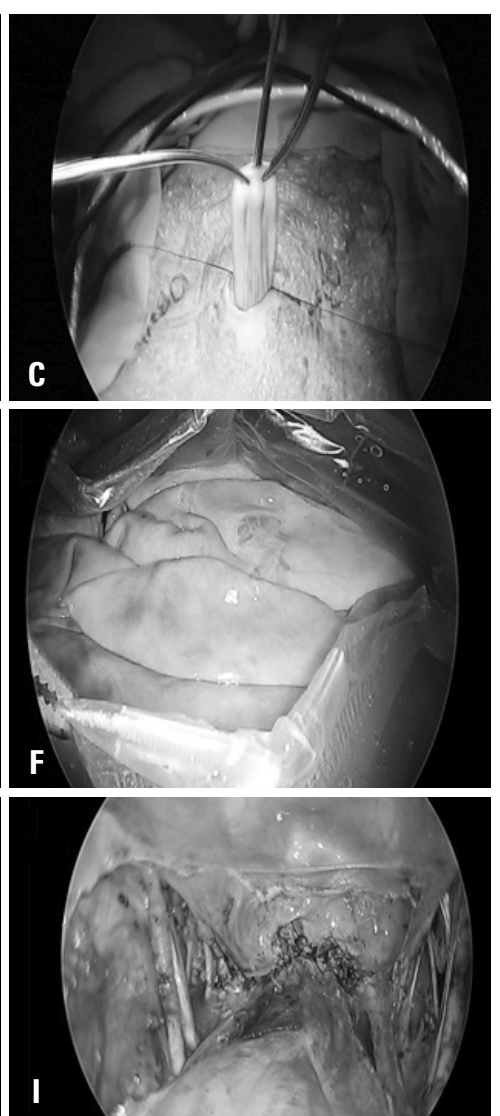

Fig. 1. Technique of laparoendoscopic single-site (LESS) surgery using an angiocatheter needle for extremely huge ovarian cysts. (A) A large ovarian cyst through a vertical $1.5-$ to $2.0-\mathrm{cm}$ incision in the umbilical area is shown. (B) An angiocatheter needle connected to a suction line is used to puncture the cyst and aspirate the cyst contents. (C) After cystic contents are aspirated, both ends of the cyst wall are clamped using Kelly clamps. A 5-mm suction tip is inserted after the incision in the puncture hole is extended. (D) After complete suction, the puncture hole of the cyst is closed by purse string suture with 2-0 Vicryl to prevent spillage during LESS surgery. (E) The decompressed ovarian cyst is shown through a Glove port in the intraabdominal cavity. (F and G) After LESS cystectomy or adnexectomy, a huge ovarian tissue is extracorporeally removed by knife-in-bag morcellation through the umbilicus. (H and I) Upon discovery of borderline or malignant tumor in a frozen section, the patient underwent surgical staging. 
the umbilicus (Fig. 1A). After the cyst wall was punctured using a 1.3- to 1.7-mm angiocatheter needle (BD Angiocath Plus ${ }^{\mathrm{TM}}$, Mississauga, Canada), its contents were aspirated with a connected vacuum aspirator (Fig. 1B). At that time, we grasped both ends of the catheter with Kelly clamps to prevent leakage. If fluid was completely aspirated, we removed the catheter and inserted a suction tip for the removal of the remnant fluid (Fig. 1C). The incision site was closed with pulse string suturing (Fig. 1D). After placing a glove port (NELLIS, Bucheon, Korea) in the umbilical incision, LESS surgery was performed using a rigid 0 -degree, 5-mm laparoscope and conventional rigid straight laparoscopic instruments, after which knife-in bag morcellation was instituted for specimen collection (Fig. 1E-G). All of the ovarian cysts were examined by intraoperative frozen biopsy. When malignant disease was confirmed by frozen biopsy, laparoscopic surgical staging operation (including pelvic lymph node dissection and para-aortic lymph node dissection) was performed (Fig. $1 \mathrm{H}$ and I). Ovarian cystectomy was performed by stripping the cyst wall from the normal ovary after removal of remnant fluid. The cyst wall was incised using monopolar scissors and dissectors.

\section{Evaluation of clinical characteristics}

We evaluated perioperative complications, conversion rate, postoperative pain, intraoperative spillage, and postoperative complications. Conversion rate included conversion to laparotomy and the use of additional ports. We also recorded operation time, the amount of blood loss, postoperative changes in hemoglobin, and the length of hospital stay.

\section{Statistical analysis}

All statistical analyses were performed with SPSS version 18.0 (SPSS, Inc., Chicago, IL, USA). Frequency analysis, such as mean \pm standard deviation, incidence rate, or percentage, was performed to analyze the characteristics and clinical outcomes of the study subjects.

\section{RESULTS}

Table 1 shows the clinical characteristics of the study subjects. The median age was 39 (range, 15-82) years, and $58.0 \%$ of the patients were nulliparous. The median diameter of the ovarian cysts was 18.5 (range, 15-30) cm, and the most common finding was abdominal palpable mass (45.1\%). The median CA125 level was 28.6 (range, 6.7-175.0) IU/mL, and the median CA19-9 level was 14.4 (range, 0.7-282.3) IU/mL.

The final pathological diagnoses are shown in Table 2 . Nineteen patients (61.3\%) were diagnosed with benign ovarian cysts, 7 patients (22.6\%) with borderline malignancy, and 5 patients (16.1\%) with malignant ovarian cancer. Table 3 shows surgical outcomes. Twenty-nine (93.5\%) patients underwent scheduled surgery, 9 (29\%) patients underwent unilateral salpingo- oophorectomy, 7 (22.6\%) patients underwent unilateral ovarian cystectomy, 5 (16.1\%) patients underwent bilateral salpingooophorectomy, $2(6.5 \%)$ patients underwent bilateral ovarian cystectomy, and 6 (19.4\%) patients underwent cytoreduction or staging operation based on their frozen biopsy results. Among the patients, 19 underwent unilateral or bilateral oophorectomy. Conversion to laparotomy was noted in 1 patient due to advanced stage ovarian cancer. The median operation time was 150 (range, 80-520) minutes, and the spillage of cyst contents occurred in 1 case due to cyst rupture during cyst wall

Table 1. Characteristics of the Study Subjects ( $n=31)$

\begin{tabular}{lc}
\hline \multicolumn{1}{c}{ Characteristics } & Values \\
\hline Age (yr) & $39(15-82)$ \\
Parity & \\
\hline Nulliparous & $18(58.0)$ \\
\hline Parous & $13(42.0)$ \\
Menopause & $22(71.0)$ \\
\hline No & $9(29.0)$ \\
\hline Yes & $18.5(15.0-30.0)$ \\
Preoperative mass size (cm) & \\
\hline Symptom and sign & $3(9.7)$ \\
\hline Asymptomatic & $1(3.2)$ \\
\hline Indigestion & $1(3.2)$ \\
\hline Abdominal distension & $2(6.5)$ \\
\hline Abdominal discomfort & $14(45.1)$ \\
\hline Abdominal palpable mass & $5(16.1)$ \\
\hline Abdominal pain & $1(3.2)$ \\
\hline Vaginal bleeding & $2(6.5)$ \\
\hline Menstrual disorder & $2(6.5)$ \\
\hline Urinary symptom & $28.6(6.7-175.0)$ \\
\hline CA125 (IU/mL) & $14.4(0.7-282.3)$ \\
CA19-9 (IU/mL) & $24.3(17.2-37.5)$ \\
\hline BMI (kg/m²) & \\
\hline BMl body mass & \\
\hline
\end{tabular}

BMl, body mass index.

Values are presented as $n(\%)$ or median (range) unless otherwise indicated.

Table 2. Final Pathological Diagnosis of the Study Subjects ( $n=31)$

\begin{tabular}{lc}
\hline \multicolumn{1}{c}{ Pathological diagnosis } & Values \\
\hline Benign & $10(32.2)$ \\
\hline Mucinous cystadenoma & $3(9.6)$ \\
\hline Serous cystadenoma & $4(12.9)$ \\
Mature cystic teratoma & $2(6.5)$ \\
\hline Endometrioma & \\
Borderline malignancy & $5(16.1)$ \\
Mucinous borderline malignant tumor & $2(6.5)$ \\
Serous borderline malignant tumor & \\
Malignancy & $1(3.2)$ \\
\hline Clear cell carcinoma & $2(6.5)$ \\
$\quad$ Mucinous cystadenocarcinoma & $2(6.5)$ \\
\hline Immature teratoma & \\
\hline Values are presented as $n(\%)$. &
\end{tabular}


Table 3. Surgical Outcomes ( $n=31$ )

\begin{tabular}{|c|c|}
\hline Outcomes & Values \\
\hline \multicolumn{2}{|l|}{ Scheduled surgery } \\
\hline Scheduled & $29(93.5)$ \\
\hline Emergency & $2(6.5)$ \\
\hline \multicolumn{2}{|l|}{ Surgical procedure } \\
\hline Unilateral salpingo-oophorectomy & $9(29.0)$ \\
\hline Unilateral ovarian cystectomy & $7(22.6)$ \\
\hline Bilateral salpingo-oophorectomy & $5(16.1)$ \\
\hline Bilateral ovarian cystectomy & $2(6.5)$ \\
\hline Unilateral oophorectomy & $1(3.2)$ \\
\hline Fertility sparing cytoreductive surgery & $3(9.7)$ \\
\hline Laparoscopic surgical staging for borderline malignant tumor & $1(3.2)$ \\
\hline Laparoscopic surgical staging for ovarian cancer & $2(6.5)$ \\
\hline Conversion to laparotomy & $1(3.2)$ \\
\hline Operation time (min) & $150(80-520)$ \\
\hline Estimated blood loss (mL) & $100(20-800)$ \\
\hline \multicolumn{2}{|l|}{ Spillage of cystic content } \\
\hline No & $30(96.8)$ \\
\hline Yes & $1(3.2)$ \\
\hline Decreased $\mathrm{Hb}(\mathrm{g} / \mathrm{dL})$ & $2(0.1-4.1)$ \\
\hline Postoperative hospital stay (days) & $3(2-22)$ \\
\hline \multicolumn{2}{|l|}{ Report of frozen biopsy } \\
\hline Benign & $21(67.7)$ \\
\hline Borderline malignancy & $7(22.6)$ \\
\hline Malignancy & $3(9.7)$ \\
\hline \multicolumn{2}{|l|}{ Results of final pathological diagnosis } \\
\hline Benign & $19(61.3)$ \\
\hline Borderline malignancy & $7(22.6)$ \\
\hline Malignancy & $5(16.1)$ \\
\hline \multicolumn{2}{|l|}{ Use of additional port } \\
\hline Yes & $0(0.0)$ \\
\hline No & $31(100.0)$ \\
\hline Follow-up periods (mon) & $22(4-60)$ \\
\hline Postoperative/perioperative complication & $0(0.0)$ \\
\hline
\end{tabular}

$\mathrm{Hb}$, hemoglobin.

Values are presented as $\mathrm{n}(\%)$ or median (range) unless otherwise indicated. dissection. The median length of hospital stay was 3 (range 2-22) days. No patient needed additional laparoscopic ports. The median follow-up period was 22 (range 4-60) months, and there were no complications during the follow-up period. Among patients who were diagnosed with borderline malignancy (mucinous borderline malignancy), one experienced development of malignant epithelial ovarian cancer after 22 months, and the remaining have been healthy until now. Three patients who were diagnosed with epithelial ovarian cancer (mucinous or clear cell carcinoma) were treated with adjuvant combination chemotherapy (carboplatin area under the curve 4 plus paclitaxel $175 \mathrm{mg} / \mathrm{m}^{2}$ for every 3 weeks) after operation. Two patients who were diagnosed immature teratoma received adjuvant combination chemotherapy (cisplatin 100 $\mathrm{mg} / \mathrm{m}^{2}$ plus etoposide $100 \mathrm{mg} / \mathrm{m}^{2}$ for every 3 weeks). One patient with advanced clear cell carcinoma died 18 months after operation due to disease progression. The other patients who were diagnosed with malignant ovarian cancer are still healthy without recurrence.

\section{DISCUSSION}

This study analyzed the surgical outcomes of huge ovarian cysts that were treated with LESS surgery. The number of studies on laparoscopic surgery of large ovarian cysts is limited, and most of them reported on cysts $\geq 10 \mathrm{~cm}$ in the longest diameter. Our study evaluated the surgical outcomes of huge ovarian cysts $\geq 15 \mathrm{~cm}$ in the longest diameter. The conversion rate was $3.2 \%$, and none of the patients experienced perioperative or postoperative complications. Therefore, we deemed LESS surgery using an angiocatheter needle to be safe and feasible, showing relatively good outcomes with short hospital stay, decreased postoperative pain, and good cosmetic results.

Many authors have attempted to develop appropriate surgical methods for huge ovarian cysts (Table 4). Some authors used surgical methods combined with LESS surgery to de-

Table 4. Comparison of Surgical Outcomes among Previous Studies

\begin{tabular}{|c|c|c|c|c|c|}
\hline & Number of study subjects (n) & Tumor size, mean (range) (cm) & Surgical method & Cyst spillage (n, \%) & Conversion (n, \%) \\
\hline$Y i^{11}$ & 3 & $23.1(13.9-34.0)$ & Combination $^{\dagger}$ & $0(0.0)$ & $0(0.0)$ \\
\hline Kim, et al. ${ }^{12}$ & 22 & $11.9(11.6-20.0)$ & Combination & $2(9.1)$ & $1(4.5)$ \\
\hline Lee, et al. ${ }^{13}$ & 12 & $18(15-30)$ & Multiport laparoscopy & & \\
\hline Hong, et al..$^{14}$ & 52 & $17(15-40)$ & Multiport laparoscopy & & \\
\hline Moulton, et al. ${ }^{15}$ & 322 & $6.4(4.3-8.7)$ & LESS surgery & & $22(6.8)$ \\
\hline Takeda, et al. $^{8}$ & 35 & $17.7(8.8-42.4)$ & LESS surgery & & \\
\hline Sagiv, et al. ${ }^{17}$ & 21 & $2844(10000-11000) \mathrm{mL}^{*}$ & & & \\
\hline Vizza, et al. $^{2}$ & 25 & $26(15-60)$ & Open laparoscopy & $1(4.0)$ & $0(0)$ \\
\hline Vlahos, et al. $^{9}$ & 53 & $8.4(7-15)$ & Multiport laparoscopy & $0(0)$ & $0(0)$ \\
\hline Song, et al. ${ }^{10}$ & 21 & $21.1(15.9-29.3)$ & Combination & $2(9.5)$ & $1(4.7)$ \\
\hline This study & 31 & $18.5(15-30)$ & LESS surgery & $1(3.2)$ & $1(3.2)$ \\
\hline
\end{tabular}

LESS, laparoendoscopic single site.

*Tumor volume (mL); ${ }^{+}$Combined with extracorporeal surgery and laparoendoscopic single-site surgery. 
crease tumor volume, as well as with extracorporeal approaches to completely remove cysts. ${ }^{10-12} \mathrm{Yi}^{11}$ reported no conversion to laparotomy in their 3 cases. Kim, et al. ${ }^{12}$ used surgical techniques combined with LESS surgery and reported a mean tumor diameter, cyst content spillage rate, and conversion rate of $11.9 \mathrm{~cm}, 9.1 \%$, and $4.5 \%$, respectively. Song, et al. ${ }^{10}$ also used combined surgical treatment and reported a mean tumor diameter, cyst content spillage rate, and conversion rate of 21.1 $\mathrm{cm}, 9.5 \%$, and $4.7 \%$, respectively. Although three earlier studies were conducted on multiport laparoscopic surgery, only two reported spillage after surgery. ${ }^{9,13,14}$ Vlahos, et al. ${ }^{9}$ reported a conversion rate of $0 \%$ that was probably because the median diameter of ovarian cysts was smaller in their study than in other studies (median diameter, $8.4 \mathrm{~cm}$, range, $7-15 \mathrm{~cm}$ ). While several previous studies have been conducted on multiport laparoscopic surgery alone or in combination with other surgical procedures, ${ }^{2,9-14}$ there have only been a few studies on LESS surgery for ovarian cysts. ${ }^{8,15}$ Takeda, et al. ${ }^{8}$ performed LESS surgery on patients with huge ovarian cysts, whose median tumor diameter was smaller than ours [17.7 (range, 8.8-42.4) vs. 18.5 (range, 15-30) cm]; however, they did not report cyst spillage rate or conversion rates.

Cyst spillage and rupture are important in laparoscopic surgery. Dermoid cysts can induce chemical peritonitis and adhesion, mucinous cysts can cause pseudomyxoma peritonei, and malignant tumors can induce upstaging or port metastasis. ${ }^{9,16,17}$ Therefore, it is mandatory to avoid cyst spillage during laparoscopic surgery. Vizza, et al. ${ }^{2}$ used SAND balloon catheters during laparoscopic surgery for ovarian cysts, but failed to prevent intraabdominal spillage in 1 patient (4\%). Lee, et al. ${ }^{13}$ described a new technique using wet gauze to prevent cyst spillage and reported that fluid leakage occurred through the puncture hole (median puncture hole diameter $10 \mathrm{~mm}$ ), which was 5.9- to 7.7-fold larger than ours (1.3-1.7 mm). In our technique, the puncture hole diameter was reduced to $1.5-1.7 \mathrm{~mm}$ by using an angiocatheter needle, and we were able to prevent cyst spillage by grasping the cyst with Kelly clamps and closing the puncture hole by purse string suture, with the exception of 1 case wherein the cyst was ruptured during cystectomy. Previous investigators have used combined treatment with multiport laparoscopy, open laparoscopy, intracorporeal methods, and extracorporeal methods after aspiration of cyst contents, while we performed only LESS surgery. Another important consideration is port-site metastases during laparoscopic surgery. Ba, et al. ${ }^{18}$ reported that the local microenvironment at the trocar site and specimen delivery are more important than the chimney effect. In our study, we used a laparoscopic bag to prevent port-site metastasis.

This study has some limitations. First, the number of study subjects was small. Second, this was a retrospective study. Third, we classified the study subjects according to inclusion and exclusion criteria, and therefore, this study could have selection bias. Future studies with a larger sample size and prospective study design are warranted. In conclusion, the size of ovarian cysts may not be a strong reason for conversion from laparoscopy to laparotomy. Our surgical technique would be safe and feasible in patients with extremely huge ovarian cysts.

\section{AUTHOR CONTRIBUTIONS}

Conceptualization: Eun Kyung Park and Min Jong Song. Data curation: Eun Young Ki. Formal analysis: Eun Young Ki. Investigation: Eun Young Ki and Min Jong Song. Methodology: In Cheol Jeong. Project administration: Sung Eun Bak, Hye Sung Hwang, and Yoo Hyun Chung. Resources: Eun Kyung Park and Min Jong Song. Software: Eun Young Ki. Supervision: Min Jong Song. Validation: Eun Young Ki and Min Jong Song. Visualization: Eun Kyung Park. Writing_original draft: Eun Young Ki. Writing-review \& editing: Eun Young Ki and Min Jong Song.

\section{ORCID iDs}

Eun Young Ki $\quad$ https://orcid.org/0000-0003-1189-3310 Eun Kyung Park https://orcid.org/0000-0003-0691-7410 In Cheol Jeong https://orcid.org/0000-0001-9314-5601 Sung Eun Bak https://orcid.org/0000-0002-8497-3998 Hye Sung Hwang https://orcid.org/0000-0002-9757-7599 Yoo Hyun Chung https://orcid.org/0000-0002-7998-7041 Min Jong Song https://orcid.org/0000-0003-4645-9485

\section{REFERENCES}

1. Padilla LA, Radosevich DM, Milad MP. Accuracy of the pelvic examination in detecting adnexal masses. Obstet Gynecol 2000;96: 593-8.

2. Vizza E, Cutilloa G, Patrizi L, Saltari M, Baiocco E, Corrado G. Use of SAND balloon catheter for laparoscopic management of extremely large ovarian cysts. J Minim Invasive Gynecol 2011;18:77984.

3. Eltabbakh GH, Charboneau AM, Eltabbakh NG. Laparoscopic surgery for large benign ovarian cysts. Gynecol Oncol 2008;108:72-6.

4. Ramirez PT, Furmovitz M, Wolf JK, Levenback C. Laparoscopic port-site metastases in patients with gynecological malignancies. Int J Gynecol Cancer 2004;14:1070-7.

5. Huang KG, Wang CJ, Chang TC, Liou JD, Hsueh S, Lai CH, et al. Management of port-site metastasis after laparoscopic surgery for ovarian cancer. Am J Obstet Gynecol 2003;189:16-21.

6. Hopkins MP, von Gruenigen V, Gaich S. Laparoscopic port site implantation with ovarian cancer. Am J Obstet Gynecol 2000;182: 735-6.

7. Fader AN, Rojas-Espaillat L, Ibeanu O, Grumbine FC, Escobar PF. Laparoendoscopic single-site surgery (LESS) in gynecology: a multi-institutional evaluation. Am J Obstet Gynecol 2010;203:501.

8. Takeda A, Imoto S, Mori M, Yamada J, Nakamura H. Management of large adnexal tumors by isobaric laparoendoscopic single-site surgery with a wound retractor. Eur J Obstet Gynecol Reprod Biol 2013;166:185-9.

9. Vlahos NF, Iavazzo C, Marcopoulos MC, Alamanou A, Kouiroukidou P, Chatzidakis V, et al. Laparoscopic management of large ovarian cysts. Surg Innov 2012;19:370-4.

10. Song T, Kim MK, Kim ML, Yoon Bs, Seong SJ. Laparoendoscopic single-site surgery for extremely large ovarian cysts: a feasibility, safety, and patient satisfaction study. Gynecol Obstet Invest 2014; 
78:81-7.

11. Yi SW. Minimally invasive management of huge ovarian cysts by laparoscopic extracorporeal approach. Minim Invasive Ther Allied Technol 2012;21:429-34.

12. Kim WC, Im KS, Kwon YS. Single-port transumbilical laparoscopicassisted adnexal surgery. JSLS 2011;15:222-7.

13. Lee LC, Sheu BC, Chou LY, Huang SC, Chang DY, Chang WC. An easy new approach to the laparoscopic treatment of large adnexal cysts. Minim Invasive Ther Allied Technol 2011;20:150-4.

14. Hong JH, Choi JS, Lee JH, Son CE, Jeon SW, Bae JW. Laparoscopic management of large ovarian tumors: clinical tips for overcoming common concerns. J Obstet Gynaecol Res 2012;38:9-15.

15. Moulton LJ, Jernigan AM, Michener CM. Postoperative outcomes after single-port laparoscopic removal of adnexal masses in patients referred to gynecologic oncology at a large academic center. J Minim Invasive Gynecol 2017;24:1136-44.

16. Song MJ, Lee SJ, Yoo SH, Seo YH, Yoon JH. Single port gasless laparoscopy-assisted mini-laparotomic ovarian resection (SP-GLAMOR): reasonable treatment for large cystic ovarian tumors with suspicion of malignancy. Gynecol Oncol 2014;132:119-24.

17. Sagiv R, Golan A, Glezerman M. Laparoscopic management of extremely large ovarian cysts. Obstet Gynecol 2005;105:1319-22.

18. Ba MC, Long H, Zhang XL, Gong YF, Yan ZF, Wang S, et al. Port-site metastases and chimney effect of B-ultrasound- guided and laparoscopically-assisted hyperthermic intraperitoneal perfusion chemotherapy. Yonsei Med J 2017;58:497-504. 